\title{
An investigation of the fuel injector dedicated to the aircraft opposed-piston two-stroke diesel engine
}

The paper presents the research results of the injector construction with the modified injection nozzle. The injector is designed for a prototype opposed-piston aircraft diesel engine. The measurements were based on the Mie scattering technique. The conditions of the experiment corresponded to maximum loads similar to those occurring at the start. The measuring point was selected in line with the analysis of engine operating conditions: combustion chamber pressure at the moment of fuel delivery (6 MPa) and fuel pressure in the injection rail (140 MPa). The analysis focused on the average spray range and distribution, taking into account the differences between holes in the nozzle. As a result of the conducted research, the fuel spray range was defined with the determined parameters of injection. The fuel spray ranges inside the constant volume chamber at specific injection pressures and in the chamber were examined, and the obtained results were used to verify and optimize the combustion process in the designed opposed-piston two-stroke engine.

Key words: diesel engine, injector, opposed-piston engine, spray range

\section{Introduction}

The correct process of fuel spraying in the combustion chamber is extremely important because the engine achieves optimal operating parameters and minimizes the emission of toxic substances. Injection equipment has a significant role in the formation of an air-fuel mixture and influences the fuel flow rate from nozzles, the range of the fuel flow front and the way of distribution of fuel droplets in the combustion chamber [1]. Registration of images inside the combustion engine cylinder meets with a number of difficulties, mainly related to high temperature and pressure, limited access to the cylinder and very high dynamics of recorded phenomena [7]. However, optical techniques are becoming more and more popular, as evidenced by studies using fixed volume chambers in universities and R\&D centres in China [5], Spain [5, 9] or simulation studies conducted in centres in Korea and the USA [6] or in Germany and Slovenia [10].

The research engine was a newly designed internal Diesel engine. The unit is characterized by three cylinders with three pairs of opposed-pistons. The engine will generate a power output equal to $100 \mathrm{~kW}$ at a crankshaft rotation speed of 3800-4000 rpm, with a capacity of about 1.61 , with a Diesel cycle. The engine will be equipped with a direct Diesel injection system [3]. It was assumed initially that the chamber to test fuel spray in the engine injection analysis should maintain nitrogen or air pressure at the level of $\mathrm{P}_{\text {pow }}=5-8 \mathrm{MPa}$. Due to the examination of the spraying process only, without combustion, high temperatures will not be reached. The diameter of these chambers is in the range of $70-220 \mathrm{~mm}$, their height is $33-120 \mathrm{~mm}$, and optical access is from 2-6 sides of the chamber. The studies carried out at the Poznań University of Technology [7, 13, 14] used windows made of $30 \mathrm{~mm}$ thick quartz glass instead, which enabled the researchers to set the compression pressure at the level of $10 \mathrm{MPa}$ and to record the penetration of the spray with a camera.

In the test engine injection chamber, there is no need to install a piston inside the chamber, but it is necessary to install an injector, pressure and temperature sensors and a gas supply valve in order to maintain a given pressure during the tests. Three windows will provide optical access for sufficient observation of the spray distribution. Due to the diameter of the test engine cylinder of $65-70 \mathrm{~mm}$, the chamber parameters of $\Phi=100$ and $H=120$ can ensure convenient testing capabilities to obtain a volume of nearly $1 \mathrm{dm}^{3}$. Figures 1-4 below present a graphical documentation of constant volume chambers used in selected studies.

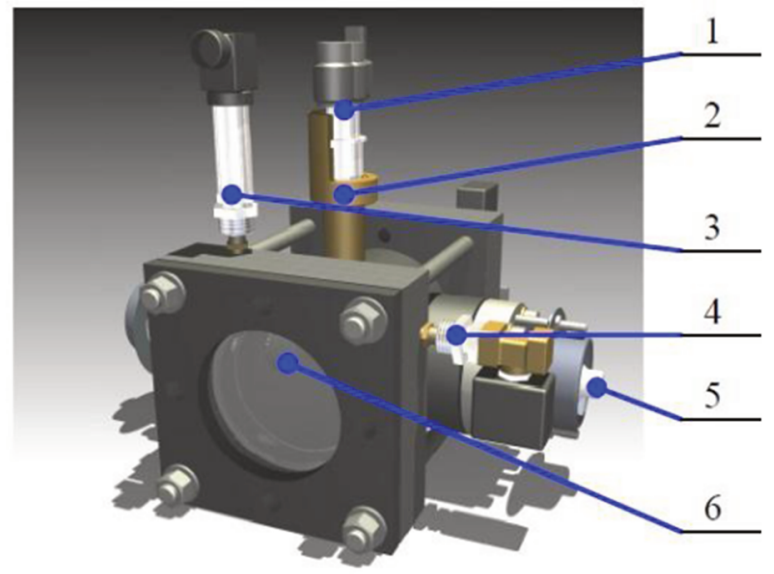

Fig. 1. View of the constant volume chamber - Poznań University of Technology: 1 - injector, 2 - injector housing, 3 - air pressure sensor, 4 - electromagnetic air valve outflow, 5 - lighting, 6 - quartz glass [13]

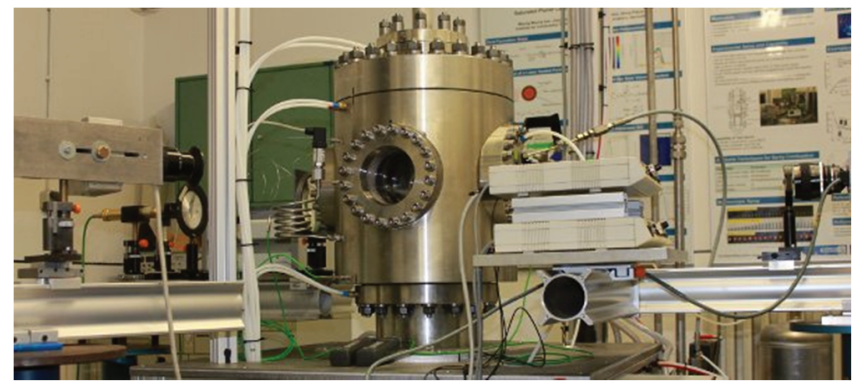

Fig. 2. Constant volume chamber at RWTH Aachen, Germany [8] 


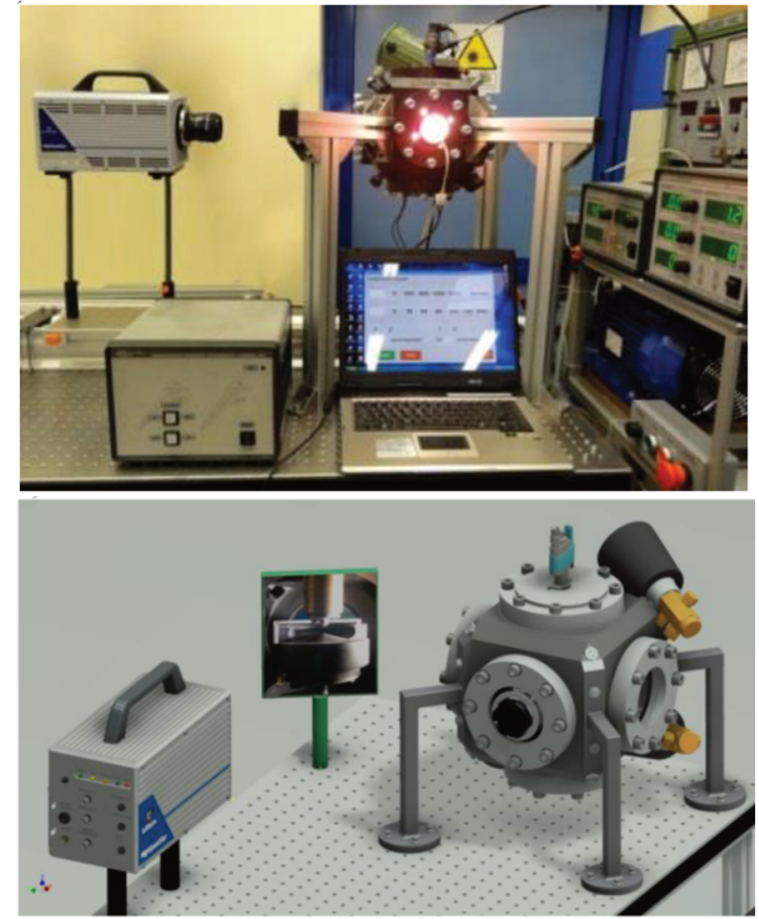

Fig. 3. A research stand for the optical tests of fuel injection and spraying process - Poznań University of Technology [13]

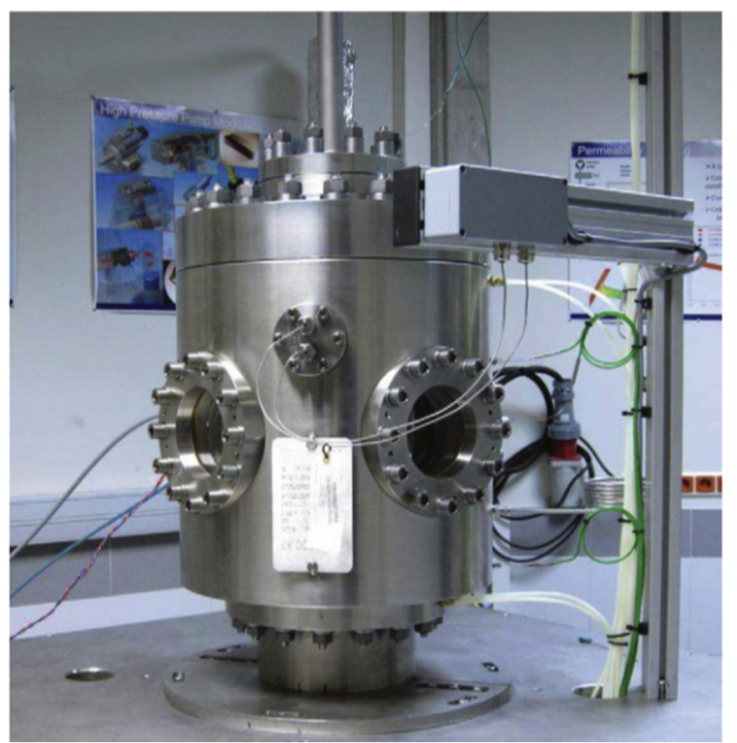

Fig. 4. Constant volume test chamber - Technical University of Valencia [11]

\section{Research scope}

In order to do the analysis of optical tests of the fuel injection process, a series of measurements of the spray range in a constant volume chamber at the injection pressure of $140 \mathrm{MPa}$ and in the chamber (counter pressure) of $6 \mathrm{MPa}$ was carried out. The aim of the research was to determine the range of the fuel spray at specific parameters of its injection. The studies were to enable the evaluation of the range of fuel spray inside the constant volume chamber at a specific injection pressure and in the chamber. The conditions of the experiment corresponded to the maximum loads similar to those occurring at the start. The measuring point was selected on the basis of the analysis of engine operating conditions: combustion chamber pressure $(6 \mathrm{MPa})$ at the moment of fuel delivery and fuel pressure in the injection rail (140 MPa).

The investigations of fuel jet penetration were carried out in a constant volume chamber with the following parameters: maximum working pressure of $15 \mathrm{MPa}$, optical access in the shape of a circle with a diameter of $160 \mathrm{~mm}$, volume of about $5.5 \mathrm{dm}^{3}$. A piezoelectric Kistler sensor (0-25 MPa) measured the pressure in the chamber, while a piezoresistive Kistler sensor (0-200 MPa) measured the fuel pressure. To generate fuel pressure, a Common Rail system with a pressure control of 0-200 MPa was used. The chamber was equipped with two M12×1.5 or M14×1.5 connections sealed on a $60 \mathrm{deg}$ cone. In order to carry out the tests, a dedicated injector mounting was made to the chamber.

The Photron FAST-CAM SA1.1 UltraHigh-Speed Video System used in this research is applied in ballistics, material research, the defence and aerospace industries, fluid dynamics and PIV. It uses a modern CMOS sensor to achieve sensitivity and speeds that were previously unavailable. Its maximum speed exceeds 600,000 fps, its global shutter operates regardless of the selected refresh rate, and its dead time between successive stages is less than a microsecond. Figure 5 shows the camera. The tests were performed at $5400 \mathrm{fps}$ and $1024 \times 1024$ resolution, which ensured optimal results.

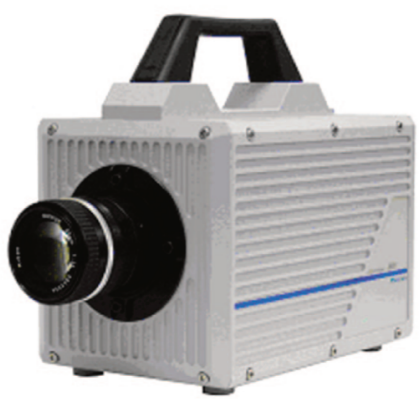

Fig. 5. Photron FASTCAM SA1.1 - a camera view [12]

The evolution of the range of the fuel spray in the highpressure chamber was measured. The research included the measurements with a high speed camera based on the Mie scattering technique with global lighting (7 repetitions for a specific measurement point).

The preparation of the test stand and measurements for a single measurement point included:

a) designing and making assembly elements of the researched injector.

b) measuring (7 repetitions) the injection at a frequency of min. $10000 \mathrm{~Hz}$ for a given injection pressure (fuel pressure) and counter pressure (chamber pressure).

c) graphic processing the collected images - determination of the relationship between the spray range and time.

The Bosch Injector No. 0445110135 was used for the optical testing of the fuel injection process. This injector is shorter than typical electromagnetic injectors. The holes in the nozzles were electro-drilled, and their edges were rounded. There are two holes with a diameter of $\Phi=0.14$ $\mathrm{mm}$, placed on the circumference every $180^{\circ}$ (Fig. 6). 

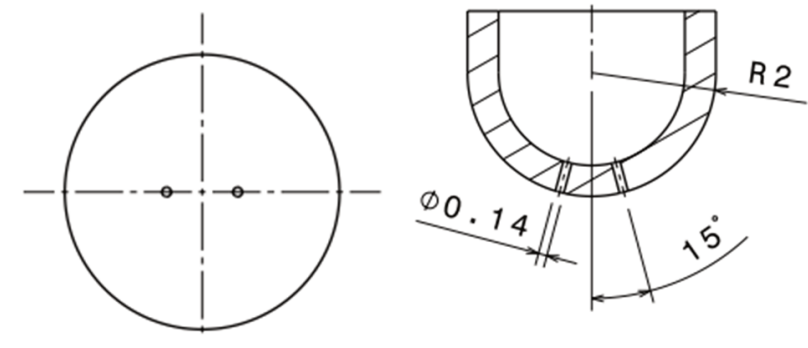

Fig. 6. Location of the spray holes

In order to determine the precise geometry of the inside of the nozzle and verify the correctness of hole welding, a tip scanning was carried out with the SkyScan 1173 device. It is a high-energy $(130 \mathrm{kV})$ micro-scanner dedicated to large objects and capable of spiral scanning allowing for a $2 \mathrm{D} / 3 \mathrm{D}$ image analysis and a realistic visualization of the internal structure with a spatial accuracy of at least $7 \mu \mathrm{m}$ [2].

Figure 7 shows the scanner capabilities on the example of the injector. Figure 8 shows the scanned tips of the nozzle used in the engine, while Figure 9 shows the scanning effects.
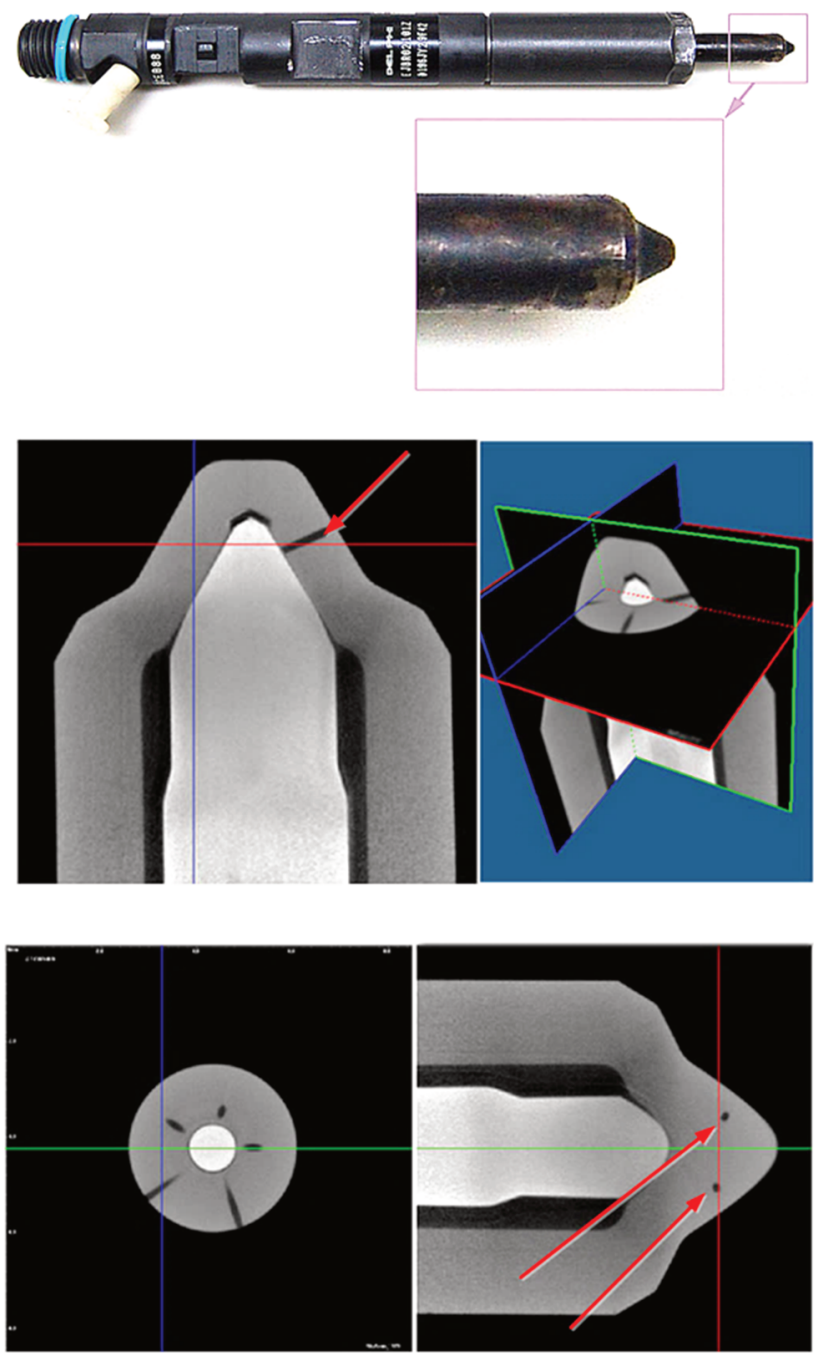

Fig. 7. Sample scanning [2]
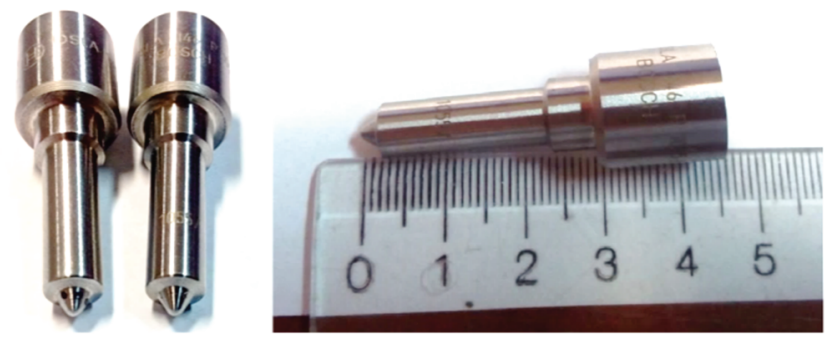

Fig. 8. Scanning of the spray tip

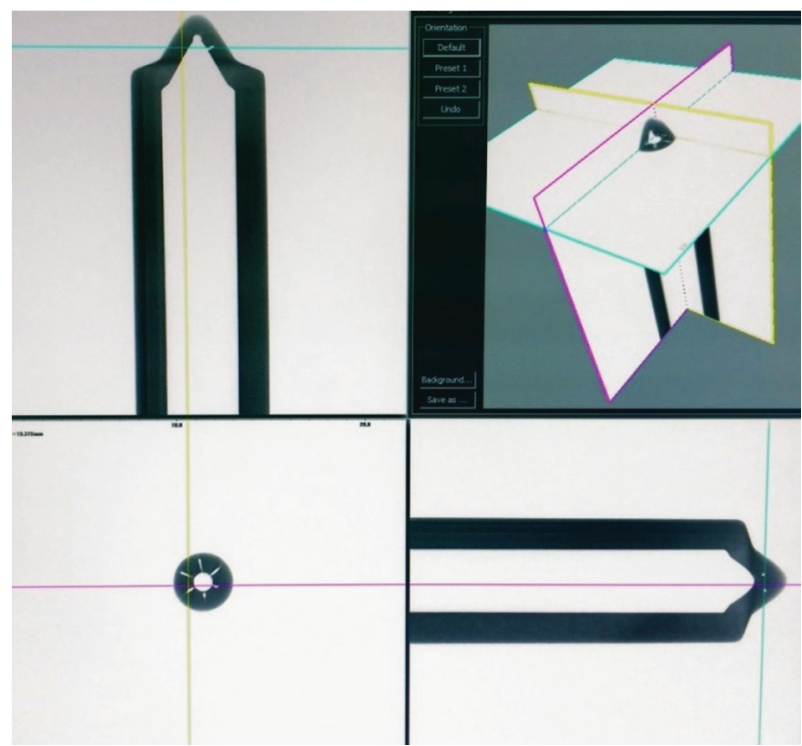

Fig. 9. Results of the scanning of the spray tip with its welded holes - scanning accuracy $10 \mu \mathrm{m}$

\section{Test results and analysis}

Figures 10 and 11 show the measurement results for seven repetitions, separately for the left and right nozzle holes. The total registration time was $10 \mathrm{~ms}$, but the most important is the period from 0 to $2 \mathrm{~ms}$, because such injection time will occur in the designed engine, for which the injector is dedicated. The diameter of the combustion chamber is $65-70 \mathrm{~mm}$. The injector is placed perpendicularly to the cylinder axis, so that the range of the spray does not exceed the dimensions of the cylinder. Obtained after

120

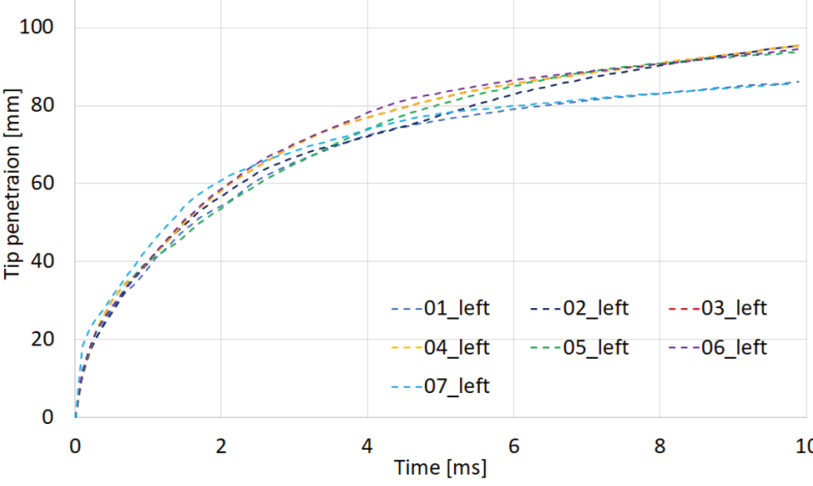

Fig. 10. Fuel spray ranges at the measurement point: injection pressure $140 \mathrm{MPa}$, in the chamber $6 \mathrm{MPa}$, left hole 
$2 \mathrm{~ms}$ range of $60 \mathrm{~mm}$ is correct, because during this time the spray does not reach the wall of the opposed-piston engine. The achieved spray ranges within $2 \mathrm{~ms}$ are repeatable, and overlapping. Initially, the shape of the curve is similar to a parabola, then, after $4 \mathrm{~ms}$, it is flattened almost to a straight line. This is due to the fact that as the distance from the atomizer increases, the kinetic energy of the stream decreases. The effect of counter pressure is also visible. Figure 12 shows the average range of the spray at the measuring point for both nozzle holes. The mean ranges from left and right holes do not differ significantly from each other. The combustion chamber is symmetrical, so the same propagation of the spray was expected.

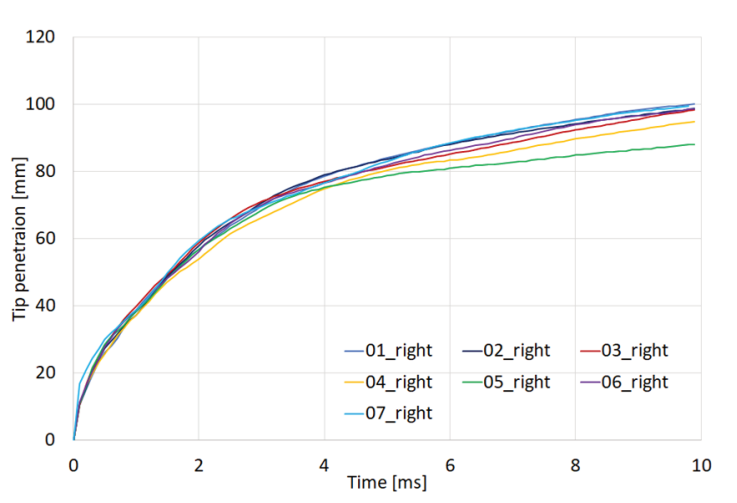

Fig. 11. Fuel spray ranges at the measurement point: injection pressure $140 \mathrm{MPa}$, in the chamber $6 \mathrm{MPa}$, right hole
Table 2 shows the images recorded at the selected period of time, showing the average range of individual sprays at the indicated measuring points. The research was carried out at a single measurement point for which 7 repetitions were made. The ranges from the left and right spray tip hole were analysed separately. The sizes of the ranges for the left and right sprays tips are significantly similar. A further development of the spray pattern results in a different size of the spray ranges because of partial evaporation of individual sprays and a change in fuel concentration at the liquid-air border [13].

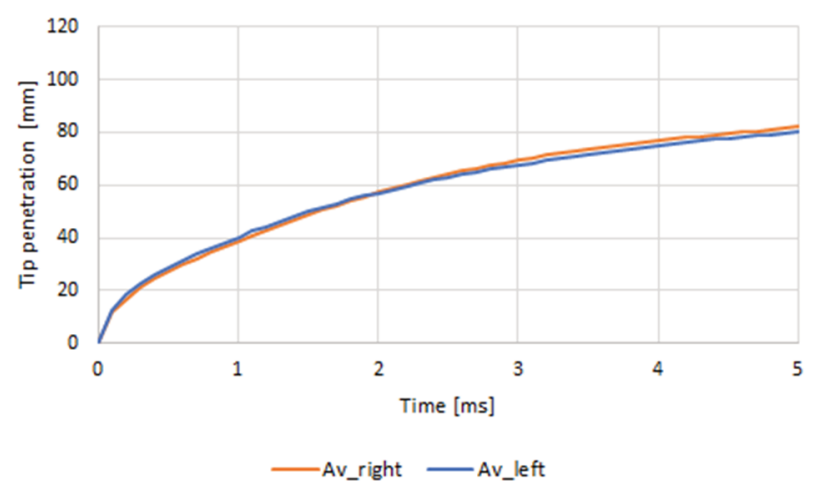

Fig. 12. Average fuel spray ranges at the measurement point: injection pressure $140 \mathrm{MPa}$, in the chamber $6 \mathrm{MPa}$

Table 2. Range of the spray at the measuring point

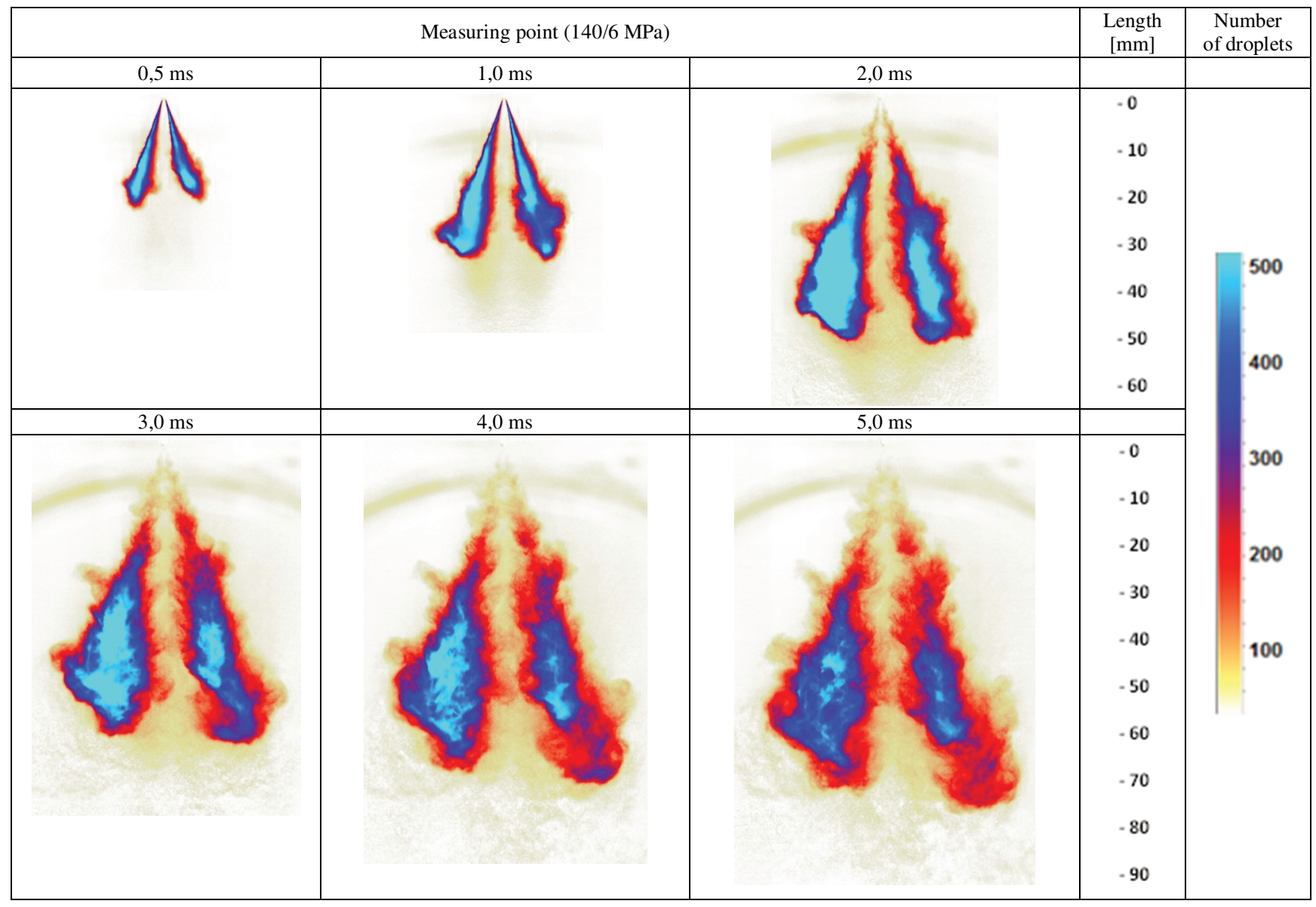




\section{Conclusions}

The research was dedicated to the spray range in the constant volume chamber with a high speed camera. The analysis of the injection process enabled us to determine the nature of fuel spraying as well as the length and speed of the spray.

As a result of the study, the range of fuel spray was determined at constant injection parameters. The fuel spray penetration ranges inside the constant volume chamber at specific injection pressures and in the chamber were examined. The obtained results will be used to verify and optimize the combustion process in the research engine.

\section{Acknowledgements}

This work has been realized in the cooperation with The Construction Office of WSK "PZL-KALISZ" S.A." and is part of Grant Agreement No. POIR.01.02.00-00-0002/15 financed by the Polish National Centre for Research and Development.

\section{Bibliography}

[1] ANDREASSI, L., UBERTINI, S., ALLOCCA, L. Experimental and numerical analysis of high pressure diesel spraywall interaction. International Journal of Multiphase Flow. 2017, 33, 742-765, DOI:10.1016/j.ijmultiphaseflow.2007. 01.003.

[2] Bruker microCT. Description SkyScan1173. 2018, http://bruker-microct.com/products/1173.htm.

[3] CZYŻ, Z., SIADKOWSKA, K., SOCHACZEWSKI, R. CFD analysis of charge exchange in an aircraft opposedpiston diesel engine. MATEC Web of Conferences, 2019, 252, 4002, DOI:10.1051/matecconf/201925204002.

[4] DESANTES, J.M., GARCÍA-OLIVER, J.M., XUAN, T. et al. A study on tip penetration velocity and radial expansion of reacting diesel sprays with different fuels. Fuel. 2017, 207, 323-335, DOI:10.1016/j.fuel.2017.06.108.

[5] DESANTES, J.M., PASTOR, J.V., GARCÍA-OLIVER, J.M. et al. An experimental analysis on the evolution of the transient tip penetration in reacting diesel sprays. Combustion and Flame. 2014, 161, 2137-2150, DOI:10.1016/j.combustflame.2014.01.022.

[6] HOON, C., REITZ, R.D. CFD simulations of diesel spray tip penetration with multiple injections and with engine compression ratios up to 100:1. Fuel. 2013, 111, 289-297, DOI:10.1016/j.fuel.2013.04.058.

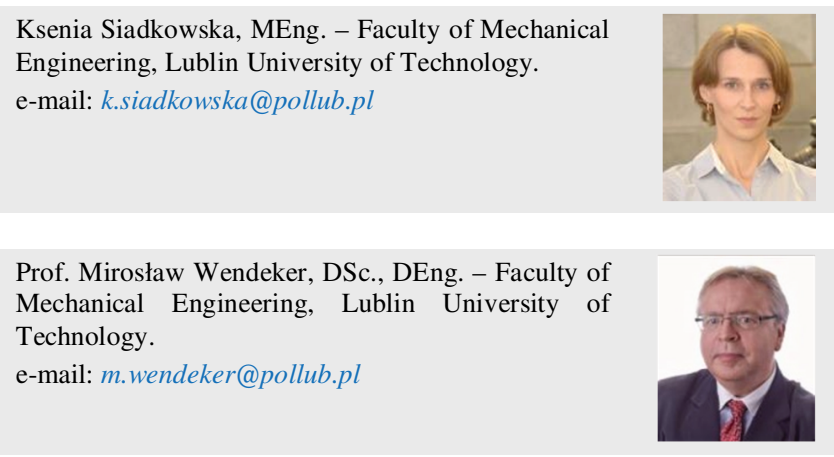

[7] IDZIOR, M., STOBNICKI, P., PIELECHA, I. et al. Research and analysis of the influence of the injection pressure on spraying fuel in the chamber about the fixed volume. Combustion Engines. 2013, 154(3), 811-819.

[8] ITV RWTH Aachen. Spraykammer. 2018, https://www.itv. rwth-aachen.de/index.php?id=41.

[9] LI, F. et al. Experimental study on spray characteristics of long-chain alcohol-diesel fuels in a constant volume chamber. Journal of the Energy Institute. 2017, C, 1-14, DOI:10.1016/j.joei.2017.11.002.

[10] MARCIC, S., MARCIC, M., WENSING, M. et al. A simplified model for a diesel spray. Fuel. 2018, 222, 485-495, DOI:10.1016/j.fuel.2018.02.152.

[11] PAYRI, R., GARCÍA-OLIVER, J.M., BARDI, M. et al. Fuel temperature influence on diesel sprays in inert and reacting conditions. Applied Thermal Engineering. 2012, 35(1), 185-195, DOI:10.1016/j.applthermaleng.2011.10.027.

[12] Photron. Specyfikacja FASTCAM SA1.1. 2018, www.photron.com.

[13] PIELECHA, I. et al. Problems of determining of fuel spray geometric parameters when based on optical investigations. Combustion Engines. 2015, 162(3), 307-315.

[14] STOBNICKI, P. Badawcza analiza wtrysku paliwa w aspekcie właściwości ekologicznych silnika o zapłonie samoczynnym. 2013.

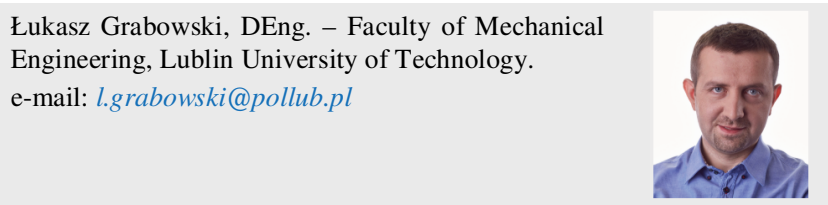

